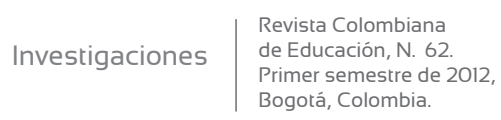

\section{Transmisión de pasados presentes. La experiencia de la Comisión de Educación de H.I.J.O.S. Regional Córdoba (Argentina)}

\author{
//Transmission of past presents the experience \\ of the Commission on Education of H.I.J.O.S. \\ Regional Cordoba, Argentina
}

//A transmissão de passados presentes. A

experiência da comissão de educação de

H.I.J.O.S. Regional Córdoba (Argentina)

Nydia Constanza Mendoza Romero*

\section{Resumen}

En el marco de los procesos de transmisión generacional de las memorias, el artículo se orienta a analizar el trabajo desarrollado por la agrupación H.I.J.O.S. Argentina (Hijos e Hijas por la Identidad y la Justicia, contra el Olvido y el Silencio), Regional Córdoba, específicamente en su comisión de educación, desde tres aspectos: las interpretaciones que sobre el pasado reciente argentino (contenidos de la memoria) les interesa transmitir, las estrategias a través de las cuales dan a conocer dichas interpretaciones y las apuestas de futuro que a partir de este proceso movilizan en el diálogo que establecen con las nuevas generaciones.

\section{Abstract}

As part of the processes of memories transmission among generations, the article aims to analyze the work done by the group Sons and Daughters for Identity and Justice Against Oblivion and Silence (H.I.J.O.S.) [Hijos e hijas por la Identidad y la Justicia contra el Olvido y el Silencio Argentina] Córdoba Regional, specifically in their education commission from three aspects: the interpretations of the recent Argentina past (memory contents) which they are interested in share, the strategies through which they disclose such interpretations and the future bets which departing from this process move the dialogue established with the new generations.

\section{Resumo}

No marco dos processos de transmissão geracional das memorias, o artigo aborda o trabalho desenvolvido pela associação H.I.J.O.S. (Hijos e Hijas por la Identidad y la Justicia contra el Olvido y el Silencio), Argentina (Regional Córdoba), especificamente em sua comissão de educação, a partir de três aspectos: as interpretações sobre o passado recente argentino (conteúdos da memória) que lhes interessa transmitir, as estratégias por meio das quais dão a conhecer essas interpretações e as apostas de futuro que a partir desse processo mobilizam no diálogo estabelecido com as novas gerações.

\section{Palabras Clave}

Memorias, transmisión de las memorias, H.I.J.O.S., educación, pasado reciente en Argentina

\section{Keywords}

Memories, transmitting of memories, H.I.J.O.S., education, recent past in Argentina.

\section{Palavras chave}

Memórias, transmissão das memórias, H.I.J.O.S., educação, passado recente, Argentina. 


\section{Presentación:}

La participación de las nuevas generaciones en la lucha por los sentidos del pasado, se constituye en un aspecto relevante en el análisis de las memorias sociales, toda vez que es allí en donde se evidencia la forma como logran condensarse las políticas de la memoria, pero también donde se reelaboran los sentidos del pasado y se perfilan distintas opciones de futuro (Aguilar, 2008).

Enmarcado en los procesos de transmisión generacional de las memorias, el artículo ${ }^{1}$ se orienta a analizar el trabajo desarrollado por la agrupación H.I.J.O.S. Argentina (Hijos e hijas por la Identidad y la Justicia, contra el Olvido y el Silencio) Regional Córdoba, específicamente en su comisión de educación, por cuanto es uno de los escenarios en los que se hace explícito su interés por transmitir determinadas interpretaciones de pasados presentes a otras generaciones.

En tal sentido, el escrito se estructura de la siguiente manera: en primer lugar se presentan algunas reflexiones a propósito de la memoria y la trasmisión generacional de las memorias, luego, se hace una breve contextualización de la agrupación H.I.J.O.S. en general y de la regional Córdoba en particular, y finalmente, se analiza el trabajo desarrollado por la comisión de educación de esta regional, desde tres aspectos: las interpretaciones que sobre el pasado reciente (contenidos de la memoria) como agrupación despliegan, las estrategias a través de las cuales dan a conocer dichas interpretaciones y las apuestas de futuro que a partir de este proceso movilizan en el diálogo que establecen con las nuevas generaciones.

\section{Algunas precisiones conceptuales}

De acuerdo con Jelin (2002) y Levín (2011a) la memoria se entiende como un proceso activo de elaboración y construcción simbólica de sentidos sobre el pasado en el que se pone en juego una estrecha articulación con las inquietudes, preguntas y necesidades del presente y con los horizontes de expectativas futuras. 
Este proceso abarca tanto las formas mediante las cuales los sujetos se relacionan individualmente con lo sucedido $^{2}$, como las modalidades que una sociedad construye para elaborar y negociar interpretaciones colectivas sobre su pasado.

En esta dinámica, la transmisión de las memorias ha sido una parte medular del contacto entre las generaciones ${ }^{3}$, por cuanto el vínculo que une la sucesión entre ellas es la difusión de historias, tradicio-

2 Esto implica considerar que cuando un sujeto "recuerda", en el sentido de traer al presente eventos de experiencias pasadas, no estamos frente a un proceso mecánico de recuperación de información previamente almacenada, ni tampoco sugiere que las imágenes y representaciones que advienen cuando se evoca el pasado sean fieles a los sentidos experimentados durante ese pasado. Por el contrario, en esa evocación se ponen en juego, sentidos, interpretaciones e imaginarios circulantes (Levín, 2011a).

3 La generación alude a la época en que cada individuo se socializa, esto es, el espacio-tiempo ligado a la edad, en el que son apropiados y reelaborados los códigos y prácticas culturales de una determinada sociedad en un momento histórico específico. También refiere a los cambios en la forma de percibir y apreciar la sociedad, los ritmos y los gustos, de allí que se señale que: "cada época tiene su episteme, y las variaciones epistémicas son percibidas y apropiadas, con toda su intensidad, durante el proceso de socialización, por los nuevos miembros que va incorporando la sociedad" (Margulis, 1996: 18). De esta forma, en los procesos de transmisión generacional, es crucial entender que la generación más que un factor de orden biológico o mental, es un fenómeno eminentemente social, pues supone la ubicación de un grupo humano en un tiempo y un espacio histórico comunes que lo predisponen hacia una forma propia de pensamiento y experiencia y un tipo específico de acción históricamente relevante (Mannheim, 1993 [1928]). nes y normas, las cuales garantizan niveles de continuidad y cohesión en las sociedades a través de las identificaciones/desidentificaciones que se construyen entre predecesores y descendientes. Así, "todos somos depositarios y transmisores de aquello que nos han legado" (Oberti, 2006: 73) lo que hace de la transmisión una actividad y de la recepción una reelaboración, que asegura a cada generación una conexión con el pasado.

Esta relación inter-generacional no entraña una temporalidad simple, como una flecha unidireccional "que va desde el pasado hacia el futuro, o que se produce necesariamente desde los individuos adultos a los individuos jóvenes" (Dussel, 2006: 272). Por el contrario, se pone en juego el carácter "multitemporal" y cambiante de la transmisión, en la que intervienen sujetos e instituciones que imprimen sus propias huellas, mandatos, deseos y que reelaboran los contenidos y sentidos del pasado transmitido (Dussel, 2002). Así, cuando se plantea la transmisión de memorias, el tiempo pasado toma densidad en la narrativa presente y de esta forma, pasado y presente se renuevan a la luz de quienes reabren los sentidos de lo legado (Kaufman, 2006).

En contextos marcados por la represión política, como lo ocurrido en Argentina durante la última 
dictadura militar (1976-1983)4, ese intercambio puede estar cargado de silencios y silenciamientos, así como de olvidos, lo que hace que las nuevas generaciones puedan llegar al escenario público con otras visiones sobre el pasado reciente ${ }^{5}$, pero al mismo tiempo reavivar las memorias, interrogando a los mayores acerca de sus compromisos y sus vivencias en ese pasado (Jelin, 2002). ¿Qué ocurre entonces cuando el lazo social que une a las generaciones se ve alterado por la irrupción de episodios violentos, que fracturan y alteran la transmisión de relatos y saberes? ¿Cómo establecer el pasaje de una generación a otra cuando hay fisuras, vacíos y desconocimiento sobre el pasado, o más aún, cuando los relatores de ese pasado no están? (Oberti, 2006; Kaufman, 2006). Lejos de olvidar o negarse a transmitir, grupos de personas inscritas en las distintas generaciones que se vieron "directamente afectadas" ${ }^{\prime 6}$ por la represión desatada por el gobierno militar argentino, en una combinación de fuerzas heredadas y contemporáneas, se dieron a la tarea de encarar sus memorias sobre la dictadura y la posterior transición democrática. Tres de estas generaciones ${ }^{7}$ han materializado en formas organizativas como: Madres y Abuelas de la Plaza de Mayo, Familiares de Detenidos Desaparecidos y la agrupación H.I.J.O.S. Sobre esta última nos detendremos a continuación.

4 El 24 de marzo de 1976 se instaló en la Argentina un régimen militar "que pretendió producir cambios irreversibles en la economía, el sistema institucional, la educación, la cultura y la estructura social, partidaria y gremial, actuando de cara a una sociedad que, a diferencia de episodios anteriores, se presentó debilitada y desarticulada, cuando no dócil y cooperativa frente al fervor castrense" (Novaro y Palermo, 2003: 19). Así, proclamando la intención de poner fin a la escalada de conflictos sociales que para entonces se vivía en Argentina una junta de comandantes de las tres armas integrada por el genera Jorge Videla, el almirante Emilio Massera y el brigadier Orlando Agosti, comunicó al país que asumía el poder político en nombre del autodenominado "Proceso de Reorganización Nacional" anunciando, desde este apelativo "que no le bastaba intervenir sobre e Estado y las instituciones sino que la Nación misma debía ser objeto de una profunda reconstrucción, una regeneración, podría decirse, social y política" (Vezzetti, 2002: 55).

5 Nombrar como reciente a este pasado no implica una cercanía en términos de contigüidad cronológica. Se trata más bien de considerar como "reciente" eventos traumáticos cuyo prolongado proceso de elaboración reactualiza pasados relativamente distantes. El carácter de reciente tiene que ver entonces con el impacto y la vigencia de las problemáticas acontecidas en ese pasado, el cual en la medida que siguen sin resolverse y elaborarse colectivamente, es constitutivo del tiempo presente (Franco y Levín, 2007).

6 Nombrar como "afectadas directas" a estas generaciones alude al impacto profundo que la represión política ocasionó en la vida psíquica y social de muchas familias, derivada de la pérdida violenta de un ser querido, su desaparición o exilio. Tal reconocimiento no desconoce que la sociedad en su conjunto también se vio hondamente implicada por este accionar represivo, desde luego, de manera diferenciada.

7 Es importante señalar que dichas generaciones y las organizaciones en las que cristalizaron sus demandas no son homogéneas, sino que por el contrario tienen bordes flexibles e incluso opuestos. Esto implica pensar la generación "como una categoría 'construida', disputada, conflictiva" (Catela, 2001: 31). 
La agrupación H.I.J.O.S. Argentina y la comisión de educación de la regional Córdobas

De acuerdo con Bonaldi (2006) y Cueto (2009) el surgimiento de la Agrupación H.I.J.O.S. -que reúne a los hijos de desaparecidos, asesinados, ex presos políticos o exiliados por la represión de la última dictadura militar en Argentina ${ }^{9}$ - se remonta a mediados de la década de los noventa, cuando se realizan una serie de eventos y homenajes a los desaparecidos que favorecieron el encuentro de varios "hijos"10, lo que posibilitó el surgimiento de la agrupación en 1995 como una Red Nacional con regionales en distintas

8 Es importante clarificar que los análisis aqu presentados no pretenden ofrecer una visión completa o total del trabajo desarrollado por la agrupación H.I.J.O.S. Argentina en general o de la regional Córdoba en particular, más bien se constituyen en ejes de reflexión para pensar las posibilidades y límites de los procesos de transmisión que este tipo de agrupaciones adelantan en los contextos escolares.

9 Esta fue en un primer momento la composición básica de la agrupación, sin embargo, con el paso del tiempo se fue planteando una apertura total a todo aquel que compartiera sus reivindicaciones básicas.

10 En 1994 se realizó en la Facultad de Arquitectura de la Universidad Nacional de La Plata, un homenaje a los desaparecidos que trabajaron o estudiaron en esa institución. Posteriormente en 1995 se realizó un encuentro de hijos organizado por el Taller "Julio Cortazar" que agrupaba a varios familiares de presos y desaparecidos en la ciudad de Córdoba (Cueto, 2009). Experiencias similares se organizaron también en Santiago del Estero y Capital Federal. provincias del país (Bonaldi, 2006) e incluso en algunas ciudades en el exterior ${ }^{11}$.

Las regionales integrantes de la Red Nacional ${ }^{12}$, tienen como lineamientos básicos los siguientes: la horizontalidad y la voluntad de consenso como mecanismo para la toma de decisiones, la restitución de los hermanos apropiados, la reivindicación de la lucha de los padres y sus compañeros, la condena social y legal a los asesinos responsables del genocidio y sus cómplices, y la reconstrucción de los lazos solidarios destruidos por la dictadura, entre otros (página web H.I.J.O.S regional Córdoba, consultada: 8/06/2011).

11 ¿Qué condiciones posibilitaron el surgimiento de esta agrupación hacia mediados de la década de los noventa? En primer lugar, podría señalarse en concordancia con Lorenz (2002) y Pastoriza (2009) que para este momento se vivía en Argentina un "boom de la memoria" y la reinstalación de la discusión política acerca de la identidad de los desaparecidos. En segundo lugar, se pone en juego la edad de los integrantes de la agrupación, toda vez que: "nacidos la mayor parte de ellos en los años previos o inmediatamente posteriores al golpe militar de 1976, tenían a mediados de los años noventa la edad en la que comienzan a plantearse la militancia política o social como un alternativa posible" (Bonaldi, 2006: 145). Finalmente, una tercera condición clave en el surgimiento de la agrupación, fue el acumulado político que hasta ese momento había ganado el movimiento de derechos humanos en Argentina del cual los integrantes de H.I.J.O.S. fueron uno de sus principales herederos (Bonaldi, 2006)

12 A la fecha (octubre de 2011) la Red Nacional está conformada por las regionales: Salta, Tucumán, Córdoba, Paraná, Mar del Plata, Chaco, Rosario, Jujuy, Rio Cuarto y Capital Federal. 
Específicamente la regional Córdoba ${ }^{13}$, cuenta con seis comisiones: educación, hermanos, escrache, recepción, memoria y comunicación $\mathrm{n}^{14}$. También se encuentra el Área de Legales, Investigación y Comunicación (ALIC), la cual se avoca a desarrollar investigaciones "para reconstruir la verdad histórica y aportar pruebas judiciales que nos permitan condenar a los imputados de los delitos de lesa humanidad" (página web H.I.J.O.S. Regional Córdoba, consultada: 8/06/2011).

La comisión objeto de análisis: educación, se orienta a "poner en discusión, en distintos ámbitos educativos, el terrorismo de Estado, las políticas instauradas durante la dictadura y sus continuidades con el presente" (página web H.I.J.O.S. Regional Córdoba, consultada: 8/06/2011). Esta comisión, en un primer momento se denominó "comisión escuelas" por el lugar al que eran convocados algunos de sus integrantes para que llevaran a cabo charlas sobre su experiencia como hijos o sobre la agrupación. Las motivaciones para realizar dichas charlas, partían del diagnóstico que elaboraron sobre la poca o nula reflexión que existía en las escuelas respecto a lo ocurrido durante la dictadura militar, como resultado de las "políticas de impunidad" auspiciadas desde el gobierno de Carlos Menem (1989-1999)15,

13 En los más de quince años de trabajo que lleva la agrupación H.I.J.O.S. Regional Córdoba, es posible advertir los cambios y continuidades en sus discursos, demandas, estrategias de trabajo y formas de relación. Esto se explica por su dinámica interna (cambios vitales de sus integrantes, reflexiones políticas y reorganizaciones administrativas), pero también, por los giros y reelaboraciones que operan en las narrativas públicas sobre el pasado reciente en Argentina (Rabotnikof 2007, Lvovich y Bisquert 2008); así como, por las transformaciones ocurridas en las políticas de memoria oficiales, particularmente desde el 2003 con el gobierno de Néstor Kirchner (Dutrénit y Varela, 2010).

14 La comisión hermanos tiene como objetivo restituir las identidades de los niños que fueron apropiados durante la última dictadura militar, a través de un proceso de investigación de los casos de manera conjunta con la organización Abuelas de la Plaza de Mayo-Córdoba. La comisión escrache, lleva a cabo una de las prácticas distintivas de la agrupación: evidenciar en el espacio público la impunidad de la que gozan los represores por la inacción de la justicia. La comisión recepción, está destinada a vincular a los nuevos integrantes en la historia y las prácticas desarrolladas por la agrupación. La comisión memoria, que se encuentra articulada a los sitios de memoria de la provincia (antiguos Centros Clandestinos de Detención), se orienta a trabajar en la reconversión de estos lugares en espacios de educación, defensa y vigencia de los derechos humanos. (página web H.I.J.O.S. Regional Córdoba, consultada: 8/06/2011). Finalmente la comisión de comunicación, apunta a visibilizar el resto de las acciones que desarrolla la agrupación principalmente a través del sitio web: www.hijos.org.ar (Notarfrancesco y Chit, 2009).

15 Según Pereyra (2007), para la década de los noventa, "la dificultad de transmitir una historia que había dejado heridas profundas y que aún marcaba dramáticamente la agenda pública del gobierno amparó una política oficial que estuvo más cerca de la pasividad o la inacción. El gobierno nacional no pareció prestar ninguna atención especia a los mecanismos tendientes a hacer ingresar esta historia en la escuela. La ausencia de políticas oficiales condujo a que la transmisión de ese período de nuestra historia quedara librada al especial compromiso y sensibilidad de actores individuales. Así, las realidades fueron tan variadas como lo eran los posicionamientos particulares y privados de cada docente o directivo, que en no pocas ocasiones, actuaba al ritmo de la inquietud del estudiantado y de la presión de los incipientes centros de estudiantes" (Pereyra, 2007: 128) 
pero también por el interés de movilizar la interpretación que como H.I.J.O.S. han construido sobre ese pasado represivo. El desarrollo de estas charlas, que comenzaron a finales de la década de los noventa y se incrementaban en las fechas próximas al 24 de marzo ${ }^{16}$, generó inquietudes en varios de los integrantes sobre la incidencia que éstas tenían y sobre las metodologías más pertinentes para trabajar con los estudiantes escolares.

Pero bueno, siempre algún profesor piola que terminaba invitando, siempre para el contexto del 24 había como bastante demanda, pero bueno estas eran un poco las preguntas que teníamos en la cabeza tenían que ver con esto: ¿Cómo hablarle a un pibe de estos temas sin que le parezca que está hablando de algo que está pasado y pisado? ¿Cómo desde esta prácti-

16 En agosto de 2002 "el Congreso Nacional sancionó la Ley $N^{\circ} 25.633$ que instituye 'el 24 de marzo como Día Nacional de la Memoria por la Verdad y la Justicia en conmemoración de quienes resultaron víctimas del proceso iniciado en esa fecha del año 1976'. El artículo $2^{\circ}$ dispone que las autoridades educativas de las distintas jurisdicciones junto al Ministerio de Educación de la Nación 'acordarán la inclusión en los respectivos calendarios escolares de jornadas alusivas al Día Nacional (...), que consoliden la memoria colectiva de la sociedad, generen sentimientos opuestos a todo tipo de autoritarismo y auspicien la defensa permanente del Estado de Derecho y la plena vigencia de los Derechos humanos'. Posteriormente, en marzo del 2006, por Ley $N^{\circ} 26.085$, se declaró el 24 de marzo como feriado nacional" (Pereyra, 2007: 143). ca poder aportar a construir una cultura contra la impunidad? Y en eso fue leer y pensar mucho (Guadalupe, integrante H.I.J.O.S. Córdoba).

Estas experiencias, motivaron el que se llevara a cabo también un trabajo con los docentes de la provincia, en tanto se reconocía que las presentaciones puntuales que los integrantes de H.I.J.O.S. realizaban no tenían la sistematicidad ni el nivel de impacto que si podía tener un profesor con el trabajo permanente con sus estudiantes. Es entonces cuando en 2003 la organización Familiares de Detenidos y Desaparecidos por Razones Políticas de Córdoba, que entre sus integrantes cuenta con varias docentes en ejercicio, planteó la posibilidad de implementar un trabajo de formación con maestros. A esta iniciativa se sumó también la organización Abuelas de Plaza de Mayo-Córdoba y los integrantes de la comisión escuelas de H.I.J.O.S.

De esta forma lograron reunirse cerca de cincuenta personas interesadas en organizar ese espacio de formación, a partir de lo cual diseñaron distintas estrategias (talleres, grupos de lectura) para poner en discusión el pasado reciente. De estos primeros encuentros se fue decantando un grupo que más tarde se denominaría como el "Vivimos" por la pregunta en torno a la cual se organizaba la reflexión de este espacio: "¿Vivimos en el país del Nunca Más?". 
Para ese momento (2007) la comisión escuelas de H.I.J.O.S. ya se denominaba comisión de educación, como resultado de las reflexiones internas de sus integrantes, pero también de su articulación al "Vivimos". En el 2008, nuevos desafíos se presentaron al grupo: el trabajo con docentes desde el Ministerio de Educación y la articulación de los integrantes de H.I.J.O.S. y del "Vivimos" a los sitios de memoria de la provincia". Estos procesos fueron resultado del interés de la agrupación por promover políticas públicas en este campo "desde la convicción de que el Estado es quien debe responsabilizarse en garantizar una educación para la memoria y los derechos humanos" (Guadalupe, integrante de H.I.J.OS. Regional Córdoba, comunicación personal).

El trabajo con docentes desde instancias como el Ministerio de Educación, implicó que el grupo "Vivimos", pensara nuevas estrategias, basándose siempre en los talleres que habían logrado sistematizar durante los primeros encuentros antes mencionados ${ }^{18}$. La vinculación a los sitios de memoria, supuso coordinar las actividades entre las áreas de educación de éstos sitios, la comisión de educación de H.I.J.O.S. y el "Vivimos", por cuanto varios de sus integrantes participaban de todos a la vez, definiéndose el "Vivimos" como el espacio articulador. En este proceso hay énfasis de reflexión, estrategias de transmisión y apuestas de formación sobre el pasado reciente, que como colectivo les interesa dar a conocer, tal y como se plantea en el siguiente apartado.

17 Por medio de la Ley 9286 del 2006 o Ley de la Memoria, se creó en Córdoba el Archivo Provincial de la Memoria, en las instalaciones de la antigua D2 (Departamento de Inteligencia de la provincia) y se definió la conformación de la Comisión Provincial por la Memoria. Estas instancias están encargadas, entre otras funciones, de preservar, difundir y acopiar nueva información relacionada con las violaciones a los derechos humanos vividos en la provincia, en el pasado reciente (www.apm.gov.ar/content/leyde-la-memoria, consultada 13/06/2011). También se abrieron al público distintos sitios de memoria, que anteriormente fungieron como Centros Clandestinos de Detención. Hasta el momento, además del Archivo Provincial, funcionan como sitios: La Perla y Campo la Ribera.

18 Tanto las elaboraciones conceptuales como las actividades para trabajar el pasado reciente se recogieron en la publicación titulada: "¿Vivimos en el país del Nunca Más? Sistematización de experiencias en educación popular y derechos humanos" y como se señala en su prólogo: "Se trata éste de un libro colectivo, que expresa la posición política y la opinión de quienes convocaron a los talleres y refleja voces de los participantes entre el 2003 y 2008 [...] Un libro de voces que se alzan y convergen como la voz de una memoria compartida" (Equipo Vivimos, 2009: 7). 


\section{"Discutiendo la Teoría de los dos Demonios". Los contenidos de la transmisión}

Son varios los contenidos que tanto a H.I.J.O.S. Regional Córdoba como al "Vivimos" les interesa transmitir: la vigencia y centralidad de los derechos humanos, las relaciones entre educación y política, el carácter dinámico de la memoria y su importancia en la lucha contra la impunidad, la relevancia de la identidad y el reconocimiento del otro, y los logros que en materia de justicia recientemente se comienzan a evidenciar en la provincia (Equipo Vivimos, 2009) ${ }^{19}$. En estos ejes de reflexión se pone en juego tanto la experiencia de trabajo y las elaboraciones conceptuales que han logrado consolidar, como sus posicionamientos políticos.

Trabajamos con una
concepción amplia de
los Derechos Humanos,
pero abordamos específi-
camente los que desde la
práctica hemos construi-
do. Sin embargo, cree-
mos que estos son ejes
transversales, que nos
sirven para pensar múl-
tiples situaciones y con-
flictos, porque el pasado
no es algo que "pasó"

19 Por cuestiones de espacio no es posible realizar un análisis pormenorizado de cada uno de estos ejes que son presentados en la publicación de "Vivimos". sino que es lo que hacemos hoy con eso que nos pasó. Es decir, que son temas actuales y visibles en la práctica, atraviesan nuestra cotidianeidad. Por otra parte, estos ejes han sido y seguirán siendo nuestros ejes de trabajo, por eso es que a partir de ellos que podemos aportar más, porque no queremos transmitir sólo contenidos (y seguro que esto también nos diferencia de otros espacios de formación docente) sino sobre todo la experiencia de la lucha, que es el lugar desde donde construimos esperanza para seguir adelante. (Equipo Vivimos, 2009: 13, el énfasis es mío).

Además de estos ejes, hay una intencionalidad explícita de los integrantes de la comisión de educación de H.I.J.O.S. y del "Vivimos" de poner en discusión la "Teoría de los dos demonios" ${ }^{\prime 20}$ porque se

20 Tras asumir la presidencia, Raúl Alfonsín (19831989) firmó los decretos 157 y 158, que ordenaba enjuiciar a jefes guerrilleros y a las tres primeras juntas de la dictadura y a partir de ello establecer: "Una lectura política del pasado reciente y la condena de la violencia desde una perspectiva que diferenciaba la legalidad y la legitimidad de sus portadores. La insurgencia se proponía como antecedente de la violencia estatal, y de hecho, la guerrilla sería la única acusada por la violencia previa al golpe, pero también serían juzgadas sus acciones tras él En cambio, el examen de la metodología ilegal usada por las Fuerzas Armadas se acotaría a período 1976-1979, los años más intensos de la represión dictatorial, y se excluiría su interven- 
reconoce que esta interpretación, al hacer una equivalencia entre las acciones de la guerrilla y el terrorismo de Estado y ubicar a la sociedad como "víctima inocente", impide una lectura multicausal y diversa de lo ocurrido durante la década de los setenta en Argentina y el desenlace del golpe militar en 1976, en tanto que:

Invisibiliza un arco extenso y variado de proyectos y prácticas políticas de construcción colectiva y de amplia base popular, que no contemplaba como metodología la acción armada en la interpelación al Estado y en la búsqueda de la toma del poder. Dicha equiparación también vuelca un manto de silencio sobre las lógicas represivas y genocidas que formaron parte de las fuerzas de seguridad tanto militares como no militares, y que lejos de responder a conductas demoníacas, individuales, y externas al conjunto social, fueron parte de un plan sistemático de control y reorganización de las prácticas sociales (Equipo Vivimos, 2009: 42).

Para el equipo "Vivimos", discutir la "teoría de los dos demonios" es central, porque se trata de la interpretación del pasado reciente más introyectada en la escuela y también porque su legado se expresa socialmente a través de: 1) las manifestaciones mediáticas que, en el marco de los juicios a los ex represores que se adelantan actualmente en Argentina, reclaman "condenar también el otro bando"21 2) el afianzamiento de miradas dicotómicas "como recurso discursivo justificatorio de nuevas políticas de represión, exclusión, discriminación" (Equipo Vivimos, 2009: 45), y 3) los reclamos que en muchas instituciones

ción bajo el gobierno de Isabel Perón [quien asumió la presidencia el 1 de julio de 1974 tras la muerte de su esposo: Juan Domingo Perón y fue depuesta de su cargo el 24 de marzo de 1976 por el golpe de Estado]. Este prisma fue caracterizado como 'la teoría de los dos demonios' pues limitaba a las cúpulas de dos actores la responsabilidad de la violencia política. Por otro lado proponía a la sociedad como ajena y víctima de ambas, y explicaba la violencia de estado, aunque no sus procedimientos, por la violencia guerrillera" (Crenzel, 2008: 58). En el Informe de la Comisión Nacional sobre la Desaparición de Personas (Conadep), esta teoría se hizo más visible cuando en el prologó se planteó que: "Durante la década del 70 la Argentina fue convulsionada por un terror que provenía tanto desde la extrema derecha como de la extrema izquierda..." y más adelante: "a los delitos de los terroristas, las Fuerzas Armadas respondieron con un terrorismo infinitamente peor que el combatido" (Conadep, 2006: 11).

21 La demanda por una "memoria completa" es una interpretación de pasado sostenida por familiares y sectores afines a las políticas de los ex represores y busca equiparar el terrorismo de Estado con las acciones armadas de la guerrilla, insistiendo en que se juzgue también a quienes habrían actuado en los "crímenes de la subversión" se trata, siguiendo a Pastoriza, de un intento por "equiparar lo inequiparable" razón por la cual "para esta visión, la justicia debería tener igual trato con todos, borrando las diferencias entre un atentado guerrillero y la represión estatal" (2009: 306) 
escolares se hace de "mirar la historia completa".

¿Qué implicaciones tiene el que una agrupación como H.I.J.O.S. ponga en discusión esta "teoría" en el contexto escolar? Podría plantearse que con este tipo de intervenciones se abre la posibilidad para que las nuevas generaciones interroguen el pasado y pongan en sospecha el carácter de "víctima inocente" en el cual fue ubicada la sociedad en su conjunto y con ello evidenciar, tanto la adhesión masiva que las movilizaciones populares habían logrado en el período anterior al golpe, así como el grado de deferencia que el gobierno militar y sus objetivos habían concitado (Rabotnikof, 2007). No obstante, emergen también otros problemas que no necesariamente se resuelven con el rechazo o distanciamiento de dicha "teoría": el funcionamiento de las organizaciones guerrilleras y la violencia política previa a la dictadura, las características y las transformaciones de las militancias, la relación entre las organizaciones armadas y otras organizaciones sociales y políticas, entre otros asuntos que, como veremos en el apartado que sigue, se plantean también como desafíos de formación para los integrantes de H.I.J.O.S. y el "Vivimos"22.

22 Como lo señala Sabato (2009), "pensar el pasado sólo en términos de dos terrorismos enfrentados es una aberración. Pero tampoco sirve hacerlo en términos de 'un demonio'. Así, aquel rechazo ha operado muchas veces como barrera que impide la formulación de ciertas preguntas clave sobre el pasado y en ese sentido ha funcionado -paradójicamente- en sintonía con las representaciones despolitizantes previas" (80)
Además, es importante no perder de vista, que este proceso de transmisión se realiza desde una posición histórica y política ${ }^{23}$ y en cuanto tal, es producto también del acumulado que han configurado las organizaciones de derechos humanos en Argentina ${ }^{24}$, en cuyo proceso han definido que estos son los aspectos que "merecen ser recordados" en detrimento de otros.

\section{Los talleres}

\section{como estrategia "imprescindible" de transmisión}

Para poner en circulación los ejes de reflexión antes mencionados, el referente pedagógico desde el que

23 En concordancia con Guelerman (2001), es preciso señalar que: "todo discurso opera desde una tradición; se trata de una posición heredada de la que no podemos escapar: todos somos hijos de una época que nos constituye más allá de nuestras propias vivencias concretas, y la mirada estará siempre en relación con lo que seamos capaces de ver" (42).

24 Según Jelin (1995) El movimiento de derechos humanos en Argentina está compuesto, por aquellas organizaciones basadas en el vínculo filial con las víctimas del terror estatal: Familiares de Detenidos y Desaparecidos por Razones Políticas, Madres de Plaza de Mayo y Abuelas de Plaza de Mayo, surgidas entre 1976 y 1977 Por otro lado, existe un grupo de organismos que pueden y suelen incluir a familiares de las víctimas, pero no se nombran a partir de ese vínculo sino en su mayoría a partir de valores universales: Liga Argentina por los Derechos de Hombre (LADH), cuya aparición data de 1937 y ha estado siempre asociada al Partido Comunista; el Servicio de Paz y Justicia (SERPAJ) y el Movimiento Ecuménico por los Derechos Humanos (MEDH), ambos de fuerte raigambre religiosa y creados en 1974 y 1976 respectivamente; y la Asamblea Permanente por los Derechos Humanos (APDH) fundada en 1975, conformada por militantes políticos de distintas extracciones $y$ de la cual se desprendió en 1979 el Centro de Estudios Legales y Sociales (CELS). 
regularmente parte tanto la comisión de educación como el "Vivimos" es la educación popular, por cuanto sus criterios básicos: la articulación entre educación y política, el carácter dialógico que se busca desde sus prácticas y el interés por generar ambientes de discusión en los que prime la horizontalidad, son los que más se acercan a los lineamientos desde los que parten como agrupación. La principal herramienta utilizada para llevar a cabo la tarea formativa es el taller, el cual se retoma por el carácter participativo que tiene, la idea de construcción colectiva que le subyace y porque se trata de un "espacio de construcción de preguntas más que de certezas [...] para el trabajo en derechos humanos y principalmente para el abordaje de la violación a los derechos humanos durante la última dictadura cívico-militar, sus continuidades y rupturas en los gobiernos democráticos posteriores" (Minatti, s.f: 8).

El cómo desarrollar los talleres y qué tipo de actividades proponer para trabajar el pasado reciente argentino forman parte de las reflexiones que permanentemente asumen los integrantes de la comisión de educación y del "Vivimos", situación que en algunos momentos ha implicado un cuestionamiento a su condición como hijos de desaparecidos y a partir de ello, una lectura problematizadora de las interpretaciones que sobre este pasado circulan en la escuela

Nosotros por ejemplo, al principio en las charlas de H.I.J.O.S. le temíamos a que salga eso, por ejemplo si vos estabas en una escuela y un chico o un docente dice: "Bueno pero entonces, si tus padres eran de tal organización, ellos mataron gente" ¿viste cómo salía en esos términos? y uno se ponía mal y no sabía cómo contestar. Después con el tiempo empezamos a provocarlo nosotros. Si no salían esas preguntas nosotros las tirábamos y eso de la forma en que lo trabajábamos. Por ahí con disparadores que le decimos, frases poco célebres, entonces bueno "¿vos has escuchado decir que con los militares estábamos mejor?, bueno ¿por qué? ¿Por qué crees que se dice eso?, ¿qué pensás vos?, o estas cosas de hubo una guerra..." (Florencia, integrante de H.I.J.O.S Córdoba). 
En particular, la experiencia de verse abocados a preguntas "incómodas" por parte de algunos estudiantes y profesores, especialmente relacionadas con la militancia política de sus padres y muy ligadas a la interpretación de la "Teoría de los dos demonios", llevó a la comisión de educación a trabajar con lo que denominaron como "frases poco célebres", las cuales han sido usadas para provocar la discusión y así lograr un mayor nivel de interpelación de los estudiantes y los docentes con quienes se realizan estos talleres ${ }^{25}$. Al respecto una de las integrantes de la comisión plantea:

Y entonces ahí empezamos a utilizar eso como disparador, desde la concepción de que estaba bueno que esto salga, porque el problema era que eso no saliera [...] Porque a nosotros no nos interesa que los pibes digan: "¡ay qué mala que fue la dictadura!" y después le digan "boliviano de mierda" al que está sentado al lado. Entonces este... ahí lo empezamos

Entre las frases elaboradas y utilizadas por la comisión y el "Vivimos" se encuentran las siguientes: "con los milicos estábamos mejor porque no había choreo ni problemas de seguridad", "no hay que insistir en temas dolorosos, hay que mirar para adelante", "está mal lo que hicieron los militares, pero había violencia de los dos lados. Los guerrilleros también mataron gente", "trabajar esos temas es muy interesante, pero son muy chicos y todavía no entienden muchas cosas", "se los llevaron porque estaban metidos en algo". (Equipo Vivimos, s.f.). a utilizar como disparador [...] entonces cuando no surgía preguntábamos nosotros: " $\mathrm{H}$ Han escuchado que con los milicos estaríamos mejor?" Yo hasta el día de hoy lo uso porque además me parece buenísima, y siempre en todas las escuelas encontrás a alguien que te dice: "si, si yo lo escuche", y "¿qué se dice? y ¿quién lo dice? y ipor qué lo dice?" Entonces ahí empezaron a salir un montón de sentidos vinculados a la dictadura, sentidos profundamente autoritarios, y a nosotros nos interesaba el autoritarismo hoy, entonces nos servía mucho (Guadalupe, integrante de H.I.J.O.S. Córdoba).

Ahora bien, el taller como estrategia privilegiada para la transmisión, tanto en H.I.J.O.S. como en el "Vivimos", no siempre es problematizado en función de las implicaciones subjetivas que conlleva; por ejemplo, no está suficientemente reflexionada la forma como al realizar un taller, los participantes son incluidos en determinados lenguajes y prácticas que son también formas particulares de sujeción. Ello impide reconocer que en tanto dispositivo pedagógico despliega relaciones de poder, que si bien posibilitan el diálogo y la construcción de posiciones 
horizontales, está en juego siempre la autoridad de quien dirige las actividades, orienta las reflexiones y provoca determinados énfasis de reflexión.

Esto desde luego no es una práctica exclusiva de esta agrupación, más bien se ha constituido como un "modo de hacer" de quienes utilizan el taller como estrategia de trabajo, en el que está implícito "un constructivismo 'natural' que postula que el sujeto aprende sólo y que el papel del maestro/adulto es guiarlo o facilitar ese proceso" (Dussel, 2002: 273). Entonces, quizás resulta central volver sobre esta estrategia con nuevas preguntas respecto a sus implicaciones, como ya comienzan a hacerlo los integrantes de la comisión de educación de H.I.J.O.S. para "desnaturalizar" y problematizar los efectos de poder y de saber que conlleva.

\section{Transmitir el pasado, transmitir el futuro}

A través de las acciones educativas que desarrollan tanto la comisión de educación como el "Vivimos", se ponen en juego no sólo contenidos y "modos de hacer" sino también visiones de sociedad a las que se busca contribuir. Así, además del interés por transmitir miradas que abran preguntas sobre el pasado reciente, trabajar con estrategias dialógicas que permita a los estudiantes y docentes establecer puentes entre ese pasado y la actualidad, y conectar las reflexiones conceptuales con una experiencia de lucha por la defensa de los derechos humanos; se vuelve crucial favorecer la participación y la organización de estudiantes y docentes.

Esto último se articula con uno de los lineamientos básicos de la agrupación H.I.J.O.S.: la reconstrucción de los lazos solidarios destruidos por la dictadura, y se justifica por los legados de silencio y apatía que dejó el gobierno militar. Por esta razón, en los talleres y charlas, se invita a los estudiantes para que tomen parte en instancias de decisión como los Centros de Estudiantes y a los docentes para que reflexionen sobre su papel como sujetos políticos y sobre las posibilidades del trabajo colectivo. Además, hay un interés explicito por aportar en la construcción cotidiana de "una cultura contra la impunidad", ya no solamente ligada a la dictadura y sus "sentidos profundamente autorita-

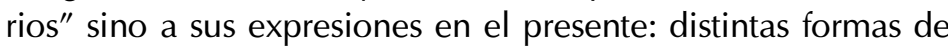
exclusión y discriminación social, y violaciones a los derechos humanos que aún persisten. 
Todos estos elementos que en buena medida apuntan a interpelar ${ }^{26}$ a los sujetos escolares, expresarían también el interés de la agrupación H.I.J.O.S. Regional Córdoba y del "Vivimos", por disputar los sentidos que desde este tipo de experiencias concretas se despliegan respecto a lo que significa construir una sociedad más democrática, solidaría y justa. Quiere decir esto que más allá de considerar estos términos como vacios de sentido, les resulta central (re)significarlos precisamente desde "la dirección de las acciones que encaramos para conseguir nuestros fines". Por ello se reconoce que la "lucha por el sentido de las cosas (y de nuestras acciones respecto a las cosas) lejos de ser algo sólo discursivo, algo superficial que no modificaría nuestro ser-en-el-mundo, es parte vital de cualquier lucha. Sólo poniendo en juego cómo vemossentimos-proyectamos el mundo, podemos continuamente abocarnos a su transformación" (Equipo Vivimos, 2009: 22).

\section{Conclusión}

En términos generales, podría pensarse como lo señala Guelerman que la "obligatoriedad" de enseñar el pasado reciente argentino,

26 Según Guelerman, en los contextos escolares un trabajo de interpelación busca "contribuir activamente en la constitución de sujetos capaces de analizar determinadas situaciones y de construir un discurso propio antes que sumarse a discursos desde los cuales se les interpele sin necesidad de análisis previo. Sujetos capaces de dudar y que necesiten hacerlo" (2001: 39-40, cursivas en el original) en particular el terrorismo de Estado, que se ha extendido por todo el sistema educativo "corre serio peligro de congelar significados que eluden el análisis y con él la posibilidad de apropiación de la historia" (Guelerman, 2001: 47). Por esta razón, para que las nuevas generaciones puedan volver sobre ese pasado como pasado y no como eterno presente, "es requisito que se les pueda ofrecer los elementos necesarios para 'conocer' y asumir la herencia de aquellos que los preceden sin temer alejarse de las huellas trazadas por las generaciones anteriores" (Oberti, 2006: 85).

Este es precisamente el desafío al que se ven avocados los integrantes de la comisión de educación de H.I.J.O.S. y el "Vivimos", por cuanto al intervenir en el contexto escolar, ponen en juego una particular manera de entender ese pasado reciente mediante la creación de espacios de reflexión, discusión y crítica entre estudiantes y docentes que se orientan a "transformar las prácticas educativas hacia un sentido más solidario y democrático" (Equipo Vivimos, 2009: 12). Hay entonces un interés explícito porque aquello que se transmite sobre lo ocurrido antes y durante la última dictadura militar, pueda ser reinterpretado activamente por los sujetos escolares y puesto en relación con nuevos contextos y referentes. Este es, en efecto, de acuerdo con Oberti (2006), el rasgo central de una "transmisión lograda". 


\section{Referencias citadas:}

Aguilar, Paloma (2008). Políticas de la memoria y memorias de la política. Madrid: Alianza.

Bonaldi, Pedro (2006). "Hijos de desaparecidos. Entre la construcción de la política y la construcción de la memoria". En: Jelin, Elizabeth; Sempol, Diego (comps.) El pasado en el futuro: los movimientos juveniles. Buenos Aires: Siglo XXI, p.p. $143-184$.

Catela, da Silva Ludmila (2001). No habrá flores en la tumba del pasado. La experiencia de reconstrucción del mundo de los familiares de desaparecidos. La Plata: Al Margen.

Crenzel, Emilio (2008). La historia política del Nunca Más. La memoria de las desapariciones en la Argentina. Buenos Aires: Siglo XXI.

Comisión Nacional sobre la Desaparición de Persona (Conadep) (2006). Nunca Más. Buenos Aires: Eudeba.

Cueto, Santiago (2009). "El surgimiento de la agrupación HIJOSLa Plata. La discusión por quiénes son las víctimas del terrorismo de Estado". En: IV Jornadas de historia política. Bahía Blanca 30 de septiembre y 1-2 de octubre de 2009. Universidad Nacional del Sur.

Dussel, Ines (2002). "La educación y la memoria. Notas sobre la política de la transmisión". En: Anclajes VI.6 Parte II, p.p. 267-293.

(2006). "A 30 años del golpe: Repensar las políticas de la transmisión en la escuela". En: Rios, Guillermo (comp). La cita secreta: encuentros y desencuentros entre memoria y educación. Santa Fe: Asociación del Magisterio de Santa Fe (Amsafe), p.p. 157-167.

Dutrénit, Silvia y Varela, Gonzalo (2010). Tramitando el pasado. Violaciones de los derechos humanos y agendas gubernamentales en casos latinoamericanos. México: Flacso-Clacso.

Franco, Marina y Levín, Florencia (2007). "El pasado cercano en clave historiográfica". En Marina. Franco y Florencia. Levín (comp.); Historia Reciente. Perspectivas y desafíos para un campo en construcción. Buenos Aires: Paidós, p.p. 31-65

Guelerman, Sergio (2001). "Escuela, juventud y genocidio. Una interpelación posible" En: Guelerman, Sergio (comp) Memorias en presente. Identidad y transmisión en la Argentina posgenocidio. Buenos Aires: Norma, p.p. 35-64

Jelin, Elizabeth (1995). "La política de la memoria: el movi- 
miento de derechos humanos y la construcción democrática en la Argentina". En: Carlos, Acuña, [et al] Juicio, castigos y memorias. Derechos humanos y justicia en la política argentina. Buenos Aires: Nueva Visión, p.p. $103-146$

(2002). Los trabajos

de la memoria. Buenos Aires: Siglo XXI.

Kaufman, Susana (2006). "Lo legado y lo propio. Lazos familiares y transmisión de memorias". En: Jelin, Elizabeth y Kaufman, Susana (comps.) Memorias de la Represión: Subjetividad y figuras de la memoria. Buenos Aires: Siglo XXI, p.p. 45-71

Levín, Florencia (2011a). Violencia, trauma y el fenómeno de la memoria, CAICYT CONICET (http://ecursos.caicyt.gov.ar), Argentina.

Lvovich, Daniel y Bisquert Jaquelina (2008). La cambiante memoria de la dictadura. Discursos públicos, movimientos sociales y legitimidad democrática. Buenos Aires: Universidad General de Sarmiento:

Mannheim, Karl (1993 [1928]). "El problema de las generaciones". En: Revista Española de investigaciones sociológicas, p.p.193244.

Margulis, Mario (1996) (Ed.). La juventud es más que una palabra. Buenos Aires: Biblos.

Novaro, Marcos. y Palermo, Vicente (2003). Historia Argentina. La dictadura militar 1976/1983.
Del golpe de Estado a la restauración democrática. Buenos Aires: Paidós.

Notarfrancesco, Martín y Chit, Julio César (2009). La Comunicación como Práctica Política. Estrategias comunicacionales de H.I.J.O.S. frente al juzgamiento de los represores de la última dictadura. Trabajo de Grado. Escuela de Ciencias de la Información. Facultad de Derecho y Ciencias Sociales. Córdoba: Universidad Nacional de Córdoba.

Oberti, Alejandra (2006). "La memoria y sus sombras" En: Jelin, Elizabeth y Kaufman, Susana (comps.) Memorias de la Represión: Subjetividad y figuras de la memoria. Buenos Aires: Siglo XXI, p.p. 73-110

Pastoriza, Lila (2009). "Hablar de memorias en Argentina". En: Vinyes, Ricad (Ed.) El Estado y la memoria. Gobiernos y ciudadanos frente a los traumas de la historia. RBA: Barcelona.

Pereyra, Ana (2007). La relación de los adolescentes con la historia reciente de Argentina. Un estudio exploratorio de la conciencia histórica entre estudiantes de escuelas medias públicas de la ciudad de Buenos Aires. Tesis de doctorado. Buenos Aires: FLACSO.

Rabotnikof, Nora (2007). "Memoria y política a treinta años del golpe". En: Lida, Clara; Crespo, Horacio y Yankelevich, Pablo 
(2007) (Comp). Argentina, 1976. Estudios en torno al golpe de Estado. Buenos Aires: Colmex-FCE, p.p. 259-284

Sabato, Hilda (2009) ( $2^{\mathrm{a}}$ ed). "La 'teoría de los dos demonios': interrogantes para una discusión". En: Schmucler, Héctor (comp) Política, violencia, memoria. Génesis y circulación de las ideas en la Argentina de los años sesenta y setenta. La Plata: Al Margen, p.p. 77-81

\section{Fuentes:}

Equipo "Vivimos" (2009). ¿Vivimos en el país del Nunca? Sistematización de experiencias en educación popular y derechos humanos. Córdoba.

Equipo "Vivimos" (s.f) Frases poco célebres. Sin publicar

Minatti, Agustín (s.f.) Propuesta de Investigación: Formación docente en Derechos Humanos. Sin publicar.

\section{Entrevistas:}

Entrevista a Florencia Ordoñez, integrante de H.I.J.O.S. Córdoba. Noviembre 17 de 2010, Córdoba, Argentina.

Entrevista a Guadalupe Samoluk, integrante de H.I.J.O.S. Córdoba. Diciembre 13 de 2010, Córdoba, Argentina.

\section{Páginas de internet}

Página web H.I.J.O.S. regional Córdoba: www.hijos.org.ar (consultada 8/06/2011)

Página web Archivo provincial de la memoria: www.apm.gov. ar/content/ley-de-la-memoria (consultada 13/06/2011). 